\title{
Relationship between saliva and free and total plasma theophylline concentrations in patients with chronic airflow obstruction
}

\author{
P EBDEN, D LEOPOLD, D BUSS, AP SMITH, PA ROUTLEDGE \\ From the Departments of Thoracic Medicine and Clinical Pharmacology and Therapeutics, Llandough \\ Hospital, Penarth, and University of Wales College of Medicine, Cardiff
}

ABSTRACT Total plasma and mixed stimulated saliva theophylline concentrations (by high performance liquid chromatography) and free plasma theophylline concentrations (by equilibrium dialysis) were measured in simultaneously collected samples from 32 outpatients receiving chronic oral theophylline treatment, who had received the drug at least two hours before sampling. There was a close relationship between saliva and total plasma theophylline concentration and between total saliva and free plasma concentration. The mean saliva to total plasma drug concentration ratio was 0.69 (SE 0.09) and the mean difference between paired saliva and free plasma concentration was $0.65(0.17) \mu \mathrm{g} / \mathrm{ml}$. It is concluded that stimulated mixed saliva provides a simple, non-invasive method of assessing total (and free) plasma theophylline concentrations during chronic oral treatment. The therapeutic range for saliva, corresponding to the generally accepted total plasma concentration range $(10-20 \mu \mathrm{g} / \mathrm{ml})$, is approximately $7-14 \mu \mathrm{g} / \mathrm{ml}$.

The measurement of plasma theophylline concentrations has been shown to be of value in management of patients with chronic reversible airflow obstruction.' Such measurements require blood sampling, which is invasive and uncomfortable and requires trained personnel. The saliva concentration of some drugs (for example, phenytoin) has been shown to be closely related to the plasma concentration of the free drug and saliva has proved to be a useful alternative method of assessing drug concentration, particularly patients for whom blood sampling is difficult or inconvenient. ${ }^{2}$

Relatively few studies have examined the relationship between saliva and plasma total theophylline concentrations and they have produced varying results in adults receiving chronic oral therapy..$^{3-6}$ Only one study examined the relationship between saliva and free (unbound) plasma theophylline concentration, ${ }^{6}$ the moiety which in part determines the saliva concentration ${ }^{2}$ and where

Address for reprint requests: Dr PA Routledge, Department of Clinical Pharmacology and Therapeutics, University of Wales College of Medicine, Cardiff CF4 2XN.

Accepted 8 February 1985 almost certainly the pharmacological action of the drug resides. We therefore measured free and total plasma and total saliva theophylline concentrations in patients who were receiving long term treatment with theophylline.

\section{Methods}

Thirty two patients ( 11 male) attending a chest outpatients department and judged by their physician to require oral xanthine preparations were studied. Their underlying diagnosis included chronic bronchitis or emphysema (or both) and asthma; their ages ranged from 20 to 80 years. The xanthine preparations used included Nuelin SA, Ronaslophylline, Theocontin, and the aminophylline preparation Phyllocontin (which contains $78 \%$ theophylline). Concurrent medication included inhaled beclomethasone, inhaled salbutamol, prednisolone, frusemide, bendrofluazide, clonidine, methyldopa, isosorbide, prothiaden, and lorazepam.

Mixed stimulated salivary samples were obtained two hours after ingestion of the theophylline preparation by asking the patient to chew Teflon tape and collect the saliva into a sterile plastic specimen tube. No specific dietary restrictions were given to 


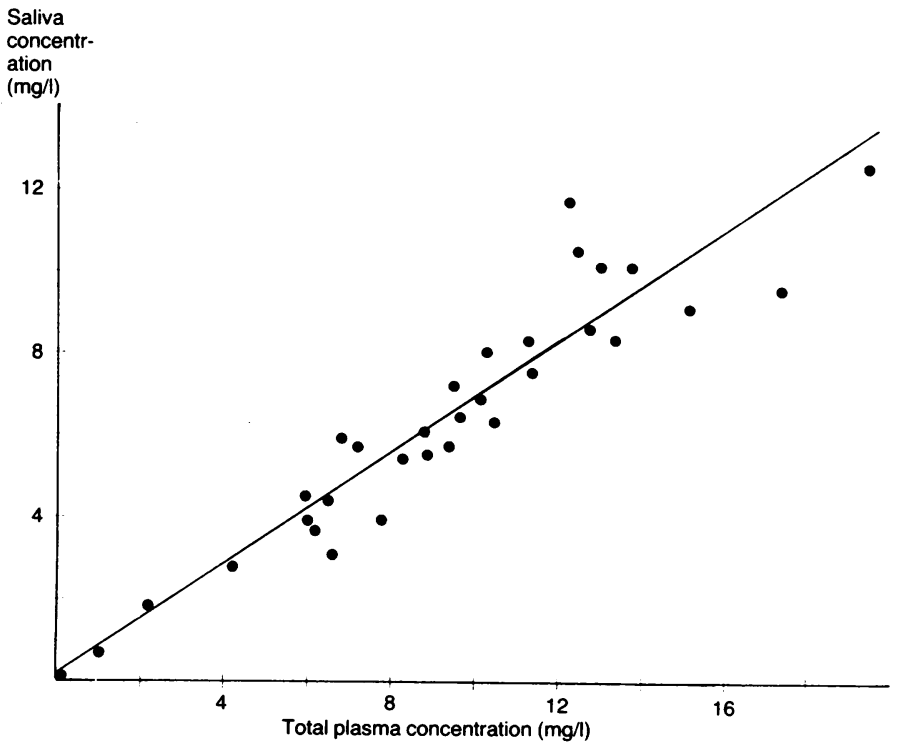

Fig 1 Relationship between salivary and total plasma theophylline concentrations in 32 subjects $(r=0.943 ; p<0.001 ; y=$ $0.67 x+0.23)$.

the patients. The saliva specimen was stored at $-20^{\circ} \mathrm{C}$ until required for analysis. At the same time as the saliva specimen was obtained blood was withdrawn by direct venepuncture into polypropylene syringes containing lithium heparin $(7.5 \mu \mathrm{g} / \mathrm{ml}$ added blood). The tubes were centrifuged immediately at $2000 \mathrm{rev} / \mathrm{min}$ and the plasma was separated and stored at $-20^{\circ} \mathrm{C}$. Plasma and saliva samples were analysed for total theophylline concentrations, high performance liquid chromatography being used. ${ }^{7}$ The free theophylline fraction was measured at $37^{\circ} \mathrm{C}$ and $\mathrm{pH} 7.4$ by equilibrium dialysis. ${ }^{8}$ The concentration of free theophylline was calculated by multiplying the total drug concentration by the free theophylline fraction. The relationship between variables was examined by least squares linear regression analysis according to Deming's technique and on the assumption of equal error variance in the measurement of plasma and saliva theophylline concentration. ${ }^{4}$

\section{Results}

The total plasma theophylline concentration in the 32 subjects ranged from $1.1-19.5 \mu \mathrm{g} / \mathrm{ml}(6.1-107.3$ $\mu \mathrm{mol} / \mathrm{l}$; mean $9.28(\mathrm{SD} 4.41 \mu \mathrm{g} / \mathrm{ml})$. The fraction of theophylline in the unbound (free) form ranged from 0.58 to 0.69 (mean $0.63(0.03)$ ). Free plasma theophylline concentrations thus varied from 0.62 to $11.6 \mu \mathrm{g} / \mathrm{ml}(3.4$ to $63.8 \mu \mathrm{mol} / \mathrm{l})$ (mean 5.80 (2.67 $\mu \mathrm{g} / \mathrm{ml}))$.

Total saliva theophylline concentrations ranged from 0.62 to $12.5 \mu \mathrm{g} / \mathrm{ml}(3.4-68.8 \mu \mathrm{mol} / \mathrm{l}$; mean
$6.45(3.02 \mu \mathrm{g} / \mathrm{ml}))$. The free fraction of theophylline in saliva measured by equilibrium dialysis in one subject was over the $\mathrm{pH}$ range 5.6-8.0.

There was a close relationship between total saliva and total plasma theophylline concentration. (fig 1). The mean saliva to total plasma theophylline

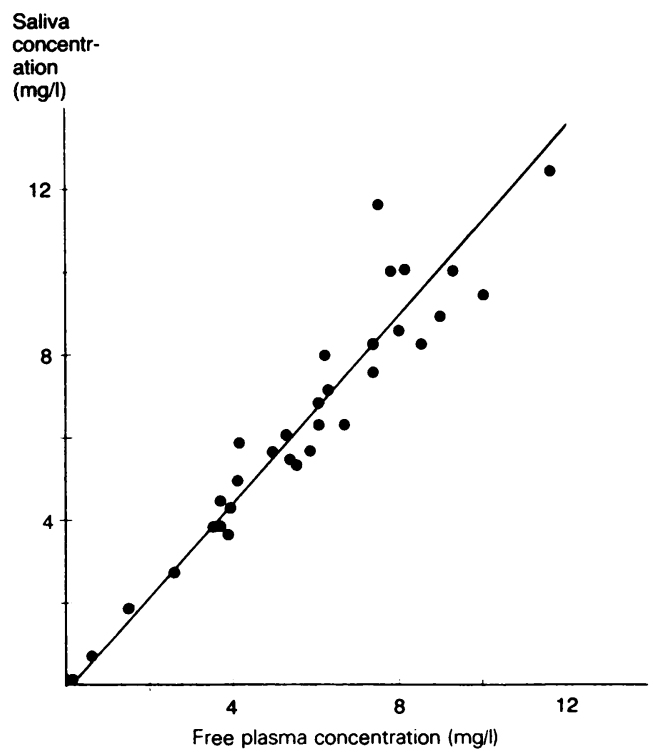

Fig 2 Relationship between salivary and free (unbound) plasma theophylline concentrations in 32 subjects $(r=0.949 ; p<0.001 ; y=1.14 x-$ 0.14). 
Published studies examining the relationship between saliva and plasma theophylline concentrations in adults after chronic dosing

\begin{tabular}{|c|c|c|c|}
\hline Source and reference & No of patients & No of samples & Mean saliva to plasma ratio \\
\hline $\begin{array}{l}\text { Patients with chronic obstructive pulmonary disease }{ }^{3} \\
\text { Patients receiving theophylline therapy } \\
\text { Asthmatic patients }^{5} \\
\text { Patients with chronic airflow obstruction } \\
\text { Patients with chronic airflow obstruction (this study) }\end{array}$ & $\begin{array}{l}23 \\
\text { Not stated } \\
16 \\
25 \\
32\end{array}$ & $\begin{array}{l}84 \\
89 \\
47 \\
25 \\
32\end{array}$ & $\begin{array}{l}0.63 \\
0.61 \\
0.70 \\
0.57 \\
0.69\end{array}$ \\
\hline
\end{tabular}

concentration ratio was 0.69 (SE 0.09). There was also a very close relationship between total saliva and free plasma theophylline concentration (fig 2). The mean saliva to free plasma theophylline concentration ratio was $1.12(0.14)$, with a mean difference between the paired values of $0.65(0.17) \mu \mathrm{g} /$ $\mathrm{ml}$.

\section{Discussion}

To our knowledge, only four studies of the relationship between saliva and total plasma theophylline concentrations in adult patients with chronic airflow obstruction receiving chronic oral theophylline therapy have been published (see table). None of these studies measured free drug, which is the concentration determining the concentration of drug in saliva as well as the concentration of drug at its effector site.

Hendeles and coworkers ${ }^{3}$ concluded that saliva theophylline concentrations did not predict plasma drug concentrations accurately. The authors used a non-specific spectrophotometric method, however, to measure saliva and plasma theophylline concentrations and although they avoided samples from patients taking drugs known to interfere with this method other sources of interference could have been present. The authors noted that saliva contamination could be caused by dentures or recent cigarette smoking, resulting in variable ultraviolet absorbance values. Moreover, samples were collected one to two hours after theophylline administration as well as just before the next dose. It is known that the relationship between saliva and plasma theophylline concentration may be perturbed for the first two hours after theophylline treatment and this could have increased the difference between measurements.

Boobis and coworkers ${ }^{4}$ measured theophylline concentrations in 89 paired stimulated saliva and plasma samples from an unstated number of adults receiving oral treatment and concluded that predictability of plasma concentration from saliva concentration was poor. They used two methods (gasliquid chromatography and enzyme immunoassay) to measure theophylline concentration, although it is not clear from the paper which method was used for particular samples. Furthermore, samples were collected one hour or more after theophylline administration rather than after two hours.

Chopra and coworkers s reported a good correlation in 47 paired samples from 16 patients receiving chronic oral theophylline treatment (Nuelin, SA). Measurements were made using high performance liquid chromatography, although the actual method is not stated. All samples appear to have been collected at least two hours after oral theophylline has been taken but they were non-stimulated.

Finally, Knott $e$ al $^{6}$ have recently reported a close correlation between saliva and plasma theophylline concentrations in 25 samples from 25 subjects receiving oral theophylline for chronic airways obstruction. The saliva samples were stimulated with citric acid, and saliva and plasma theophylline concentrations were measured by homologous enzyme immunoassay. The interval between drug administration and sampling after dosing was not specified, and the reported saliva to plasma theophylline ratio was lower than in previous studies and our own study.

From our findings we conclude that salivary concentrations are valuable in monitoring plasma theophylline concentrations in adults having chronic theophylline treatment when the stimulated saliva sample is collected at least two hours after drug administration. It is important to note, however, that a specific high performance liquid chromatography method that eliminates interference from caffeine metabolites was used and other analytical methods must be assessed before they are routinely used to monitor theophylline concentrations in saliva.

We thank Riker Laboratories for financial assistance.

\section{References}

1 Ogilvie RI. Theophylline: clinical aspects. In: Richens A, Marks V, eds. Therapeutic drug monitoring. London: Churchill Livingston, 1981:425-33.

2 Danhof M, Breimer DD. Therapeutic drug monitoring 
in saliva. Clinical Pharmacokinetics 1978;3:39-57.

3 Hendeles L, Burkley S, Bighley L, Richardson R. Unpredictability of theophylline saliva measurements in chronic obstructive pulmonary disease. $J$ Allergy Clin Immunol 1977;60:335-8.

4 Boobis S, Trembath PW, Chambers RE, Edmunds AT, Carswell F. Salivary theophylline estimations. Are they valid substitution for plasma levels? Therapeutics Drug Monitoring 1979;1:485-93.

5 Chopra MP, Addison JM, Chopra A, Higginbottam L. Plasma and saliva theophylline levels and pulmonary function in asthmatic patients after a sustained-release theophylline preparation (Nuelin SA). Curr Med Res Opin 1981; 7:624-30.
6 Knott C, Bateman M, Reynolds F. Do saliva concentrations predict plasma unbound theophylline concentrations? A problem re-examined. Br J Clin Pharmacol 1984;17:9-14.

7 Miksic JR, Hodes B. Theophylline analysis by reversed-phase high pressure liquid chromatography: elimination of interferences. Journal of Pharmaceutical Sciences 1979;68:1200-2.

8 Ebden P, Leopold D, Smith AP, Buss D, Routledge PA. Free and total plasma theophylline concentration in chronic airflow obstruction. Thorax 1984;39:352-5.

9 Deming SN, Morgan SL. The use of linear models and matrix least squares in clinical chemistry. Clin Chem 1979;25:840. 